\title{
Dialogic skills in RE: recontextualising the dialogue school
}

\author{
Antony Luby ${ }^{1}$ (D) \\ Published online: 7 June 2019 \\ (c) The Author(s) 2019
}

\begin{abstract}
As the Catholic Church encounters secularism and pluralism, one of her main responses has been dialogue. Some of the prime manifestations have been the political initiative of the Courtyard of the Gentiles and the plea from the Congregation for Catholic Education for a grammar of dialogue as envisaged in the recent document Educating for fraternal humanism. Arguably, the most developed response is to be found in the Australian Dialogue School model mooted by theologians from the Catholic University of Leuven, Belgium. This paper outlines some of the findings from a recent $\mathrm{PhD}$ thesis that examines the dialogic skills of building consensus through cumulative talk and constructive criticism through exploratory talk. It is advocated that teachers use the medium of paired conversations between students in the secondary stage of schooling in order to develop such dialogic skills.
\end{abstract}

Keywords Dialogue $\cdot$ Cumulative talk - Exploratory talk $\cdot$ Paired conversations

...I consider essential for facing the present moment: constructive dialogue... When leaders in various fields ask me for advice, my response is always the same: dialogue, dialogue, dialogue. (Pope Francis 27 July 2013; as quoted in Sherman 2015).

\section{Introduction}

In a recent issue of Journal of Religious Education, Margaret Carswell reports on the developing relationship between the Catholic Education Commission, Victoria, Australia, and the Faculty of Theology at the Catholic University of Leuven, Belgium. Indeed, this relationship has now extended to other Australian dioceses and there is widespread interest in religious education (RE) curricula '...that emphasise[s] dialogue, embrace[s] religious pluralism and promote[s] active enquiry...' (Carswell 2018, p. 213). Having spent a career lifetime teaching RE in the United Kingdom (UK); I recently had the privilege of joining with educators from Australia and participating in a study week at the Leuven Faculty of Theology. The focus of this study week was the Recontextualising Dialogue School (Pollefeyt and Bouwens 2010, 2014) that intrigued me as I was on the verge of completing

Antony Luby

a.luby.1@research.gla.ac.uk

1 School of Education, University of Glasgow, Glasgow, UK 
a $\mathrm{PhD}$ thesis on dialogic skills in the RE classroom (Luby 2019). This paper is a reflection upon these $\mathrm{PhD}$ studies and it is offered as a contribution to those Catholic educators seeking to engage with critical, dialogic RE within the context of a pluralist society.

\section{The Catholic Church and dialogue}

But why dialogue? In 2004, having spent twenty years teaching RE within UK state secondary schools (students aged 11-17 years) I accepted an invitation from the Bishop of the Diocese of Aberdeen to establish the Roman Catholic RE (RCRE) Service across ten of the state secondary schools in the city of Aberdeen. This entailed the unusual scenario of students being released from Religious and Moral Education (RME) classes for several weeks in the year in order to participate with RCRE. The prevailing confessional nature and catechetical approach of RCRE syllabi at that time in Scotland did not seem suitable for students attending schools in which a critical approach to RE predominated. Uncertain as how best to proceed, I sought guidance within theological studies at the University of Aberdeen (Luby 2006). These studies suggested that a Thomistic approach with a focus on truth might offer a solution; and so I wrote about my grappling with this issue on the very pages of this journal (Luby 2008, 2010).

Further study, though, provoked a deeper insight as a review of the literature produced rich findings with respect to the Catholic Church and her attitude towards dialogue (Luby 2012). At present, the Catholic Church adopts a positive yet robust position with regard to dialogue. One of the two French theologians who are 'lodestars' for Pope Francis is Henri de Lubac whose influence is very apparent with respect to dialogue (Ivereigh 2015). The Catholic Church is confident about dialogue with those of other faiths and of no faith (de Lubac 1995); and, sadly, she needs to be. Riven by crises, the Church's moral authority is weakened by a series of scandals and so it is with humility that the Church must engage with others: but it is humility founded upon a strong faith. Since, as Pope Francis (2013, p. 34) reminds us in his first encyclical letter, '...the security of faith sets us on a journey; it enables witness and dialogue with all'.

In practice, though, what might this witness and dialogue look like? Pope Saint John Paul II (1990, p. 56) sets down a firm marker for witness and dialogue within the Catholic Church in his encyclical letter Redemptoris Missio:

Dialogue does not originate from tactical concerns or self-interest, but is an activity with its own guiding principles, requirements and dignity... Those engaged in this dialogue must be consistent with their own religious traditions and convictions, and be open to understanding those of the other party without pretense or close-mindedness, but with truth, humility and frankness, knowing that dialogue can enrich each side. There must be no abandonment of principles nor false irenicism, but instead a witness given and received for mutual advancement...

This is a robust understanding of dialogue in which both parties, Catholic and non-Catholic, are instructed to remain true to their beliefs and to engage frankly with each other; and at the heart of such dialogue is a common pursuit of truth. As the Church's Declaration on Religious Freedom (Dignitatis Humanae) makes clear,

Truth... is to be sought in a manner proper to the dignity of the human person and his social nature. The inquiry is to be free, carried on with the aid of teaching or instruction, communication and dialogue, in the course of which people explain to one 
another the truth they have discovered, or think they have discovered [emphasis added], ${ }^{1}$ in order thus to assist one another in the quest for truth... (Pope Saint Paul VI 1965, p. 3)

A strongly dialogic approach to discovering truth is particularly well reflected within the Church's teaching concerning education. Crucially, there is here a moral imperative to take into account the needs of all students, as emphasised by the Congregation for Catholic Education (1982, Para. 14) with its assertion that,

Catholic educators... must have the greatest respect for those students who are not Catholic. They should be open at all times to authentic dialogue...

This openness to 'authentic dialogue' indicates that the educational context cannot be one that operates on 'tactical concerns or self-interest' as alluded by Pope Saint John Paul II above. If the purpose of the dialogue is simply to convert non-Catholics, then it would be inauthentic or 'a form of manipulation' (Baum 2000). To be truly authentic the Catholic students have to engage in

... respectful dialogue [emphasis added] with those who do not yet accept the Gospel. Believers can profit from this dialogue by learning to appreciate better 'those elements of truth and grace which are found among peoples, and which are, as it were, a secret presence of God.' (CCC 856)

Through participation in authentic and respectful dialogue, Catholic students can benefit from discovering 'elements of truth and grace' within their peers. For in a 'mysterious way' their peers may already be linked to the Catholic Church. Whilst it is a Catholic truth that 'outside the Church there is no salvation'-this can be misunderstood. As Pope Saint John Paul II (1995) explains ${ }^{2}$ :

...salvation is accessible in mysterious ways... It is a mysterious relationship. It is mysterious for those who receive the grace, because they do not know the Church and sometimes even outwardly reject her.

Catholics need to tread warily here as we cannot assume a superior position in our relationship with "non-Catholics" since these "non-Catholics" may be-unknown to themselves, and despite their outward protestations-mysteriously linked to the Catholic Church. Rather, in dialogue, Catholics must be genuinely open to finding "truth and grace" within their peers.

\footnotetext{
${ }^{1}$ As a Catholic teacher of RE I affirm the truth that Christ is the fullest revelation of God and that the Catholic Church has the deepest understanding of this revelation. However, in the RE classroom it is important to bear in mind that the students are striving to understand religious truth and so they will form partial conceptions and, indeed, misconceptions. Allowances should be made for this; and the students should be encouraged and enabled to continue with their discoveries about religious truth.

${ }^{2}$ See CCC (847) 'those who, through no fault of their own, do not know Christ and his Church... but who nevertheless seek God with a sincere heart, and, moved by grace, try in their actions to do his will as they know it through the dictates of their conscience-those too may achieve eternal salvation.' And also Gaudium et Spes (22) 'All this holds true not only for Christians, but for all men of good will in whose hearts grace works in an unseen way. For, since Christ died for all men, and since the ultimate vocation of man is in fact one, and divine, we ought to believe that the Holy Spirit in a manner known only to God offers to every man the possibility of being associated with this paschal mystery'.
} 


\section{Paired conversations}

The Church's teaching of authentic, respectful dialogue between Catholics and those outside of the Church was influential in the action research undertaken with twenty of my students in '...an academically high-attainment city comprehensive ${ }^{3}$ with the majority of pupils living in a relatively affluent catchment area' (Luby 2012, p. 71). The ten Catholic students paired themselves with non-Catholic peers with whom they were friendly and, prompted by texts and a dvd clip, they engaged with conversations that were recorded, transcribed and analysed for quality with respect to both cumulative talk and exploratory talk. The former type of talk aims at building consensus and is defined by Mercer (1995, p. $104)$ as '...build[ing] positively but uncritically on what the other has said'; whilst the latter type of talk is described as '...engag[ing] critically but constructively with each other's ideas.'

The students clearly enjoyed this experience as affirmed by both their one-sentence written comments and the findings from the questionnaire survey indicated that, in their estimation, they were adopting a deep approach to learning in RE. Further, there was sufficient evidence that, for the most part, the students were engaging with high levels of both cumulative talk and exploratory talk (Luby 2014). The findings were sufficiently encouraging that the next step was to promulgate and examine this dialogic RE in schools with which the author was unfamiliar.

\section{Research sample}

This research involved an opportunity sample total of ten secondary schools across the UK (9 in England; 1 in Scotland). Four of the schools were faith schools (2 Anglican; 2 Catholic) and five were state academy schools ${ }^{4}$ with the remaining secondary school being a comprehensive. This opportunity sample has a high degree of robustness when analysed through four criteria as recommended by previous research (Luby 2012, p. 82):

- Types of school;

- Levels of attainment;

- Location of schools; and

- Affluence of location.

The ten secondary schools represent the three most common types of schools-academies, comprehensives and faith schools. Although both academies and faith schools are over-represented within the opportunity sample this is acceptable given the UK Government's long term goal of "academisation" in England and the special focus for faith schools within this research. Regarding the second criterion of attainment levels, the sample skews towards the lower end of the spectrum and, arguably, this enhances the robustness of the research findings. For the third criterion, there is a spread of locations for the schools across four types of city, town, semi-rural and rural. Finally, regarding the fourth criterion, the sample is skewed towards schools that have catchment areas containing neighbourhoods of

\footnotetext{
3 A comprehensive school is open to all students from different backgrounds.

${ }^{4}$ Afforded a higher degree of autonomy within the state sector in England.
} 
Table 1 Affiliation of participants.

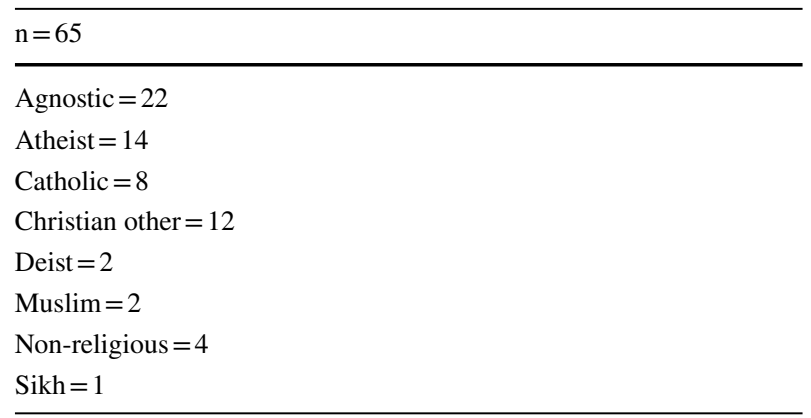

Source Luby (2019)

deprivation. Again, though, this strengthens the robustness of the research findings. Overall then, there is a broad representation of school types, attainment levels and locations.

With respect to the sixty-five students themselves the breakdown of self-declared religious and non-religious affiliation is outlined below in Table 1.

All but four of the students were in Years 10-12 (i.e. aged 14-17) and the ratio of Catholics is broadly equivalent to that pertaining within the UK. This indicates that the opportunity sample provides a degree of relatability with regard to affiliation of participants. And so to the research questions.

\section{Research Question 1}

To what extent do the students remain on-task when their conversations take place out with the visible control of the teacher?

If teachers of RE in Australia, and elsewhere, are contemplating the introduction of dialogic skills of cumulative talk and exploratory talk into their classrooms; then one of their first considerations is likely to be "Will the students remain on-task whilst outside my supervision?" This is a legitimate concern although the previous action research study by Luby (2012) might assuage such concern given that the twenty pupils were on task for more than $92 \%$ of the time. However, there are two marked differences. Firstly, as action research the previous study was undertaken by the students' own classroom teacher. This means that there was already a student-teacher relationship in place and, at the very least, the students were aware that they could be subject to disciplinary sanctions if they participated in too much off task activity. With this more recent study, though, there is no such relationship as the researcher is a stranger to the students. Practical experience indicates that there is a greater likelihood of students engaging with off task activities. Secondly, the definition of 'on task' is more rigorous with the second study as it is restricted to time spent on cumulative talk and exploratory talk; whereas with the previous study, disputational talk was acceptable. This introduces the second research question. 


\section{Prompt sheet}

1. Do you understand what your partner is saying? If not, ask her/him to explain the difficult word or idea.

2. Do you agree with anything your partner is saying? If so, let her/him know that your ideas are the same.

3. Do you disagree with her/his ideas? If so, explain why you think differently.

4. Tell her/him the problem or question that you wish her/him to think about.

Fig. 1 Prompt sheet. Source adapted from McKenna et al. (2008)

\section{Research Question 2}

To what extent does this intervention promote participation in cumulative talk and exploratory talk by the students?

In order to illustrate what actually took place, let us examine the first school in which fieldwork was conducted namely, Apostle High. ${ }^{5}$ This is a smaller than average sized Catholic secondary school situated on the outskirts of a city. It serves a large catchment area comprising both city and rural areas. Fieldwork was undertaken with thirteen studentseleven in Y13 and two in Y11 with the students self-declaring their religious affiliation as follows:

\begin{tabular}{lr} 
Agnostic & 6 \\
Atheist & 1 \\
Catholic & 5 \\
Other Christian & 1 \\
\hline
\end{tabular}

All of the students were situated in rooms close to their RE classroom. For some, their paired conversations were private in that no-one else was present; whilst for other students it was semi-private, in that they shared a room with another pair of students. The students were briefed prior to their paired conversations. This comprised an explanation about the procedure and an examination of the prompt sheet (see Fig. 1 below) to which they had access throughout the conversation. The students were provided with an opportunity to ask questions; and then they were invited to read two excerpts about science and the supernatural and historical evidences regarding the authenticity of the Gospel from the schoolbook Trial of the Resurrection.

The two criteria for determining the quality of the conversations are as follows:

5 All names of schools and students are fictional to protect anonymity. 
Table 2 Table of on task averages apostle high $(n=1)$

\begin{tabular}{|c|c|c|c|c|}
\hline Conversation & Words & $\begin{array}{l}\text { Cumulative } \\
\text { talk (\%) }\end{array}$ & $\begin{array}{l}\text { Exploratory } \\
\text { talk }(\%)\end{array}$ & On task $(\%)$ \\
\hline 1 & 2536 & 50.7 & 36.2 & 86.9 \\
\hline 2 & 2215 & 66.0 & 28.0 & 94.0 \\
\hline 3 & 2765 & 5.1 & 33.6 & 38.7 \\
\hline 4 & 847 & 22.0 & 7.4 & 29.4 \\
\hline 6 & 997 & 3.1 & 36.0 & 39.1 \\
\hline 7 & 379 & 48.5 & 11.6 & 60.1 \\
\hline 8 & 2606 & 30.4 & 40.0 & 70.4 \\
\hline 9 & 1038 & 44.9 & 51.7 & 96.6 \\
\hline 10 & 1503 & 73.5 & 25.9 & 99.4 \\
\hline 11 & 965 & 83.2 & 9.5 & 92.7 \\
\hline 12 & 1832 & 42.5 & 15.6 & 58.1 \\
\hline Average & 1607 & 42.7 & 26.9 & 69.6 \\
\hline
\end{tabular}

Source Luby (2019)

1. The number of words in the conversation; and

2. The percentage of words that are deemed "on task" i.e. comprising cumulative talk and exploratory talk.

With regard to the first criterion, from a previous study (Luby 2012), it became apparent that a conversation usually requires a minimum of 700 words to produce good levels of cumulative talk and exploratory talk; and so a minimum standard for a "high quality" conversation is that of 700 words. With respect to the second criterion of "on task" activity, achieving a conversation of "high quality" is set at $70 \%$ and above for a combination of cumulative talk and exploratory talk. Conversations that do not meet the criteria of a minimum of 700 words and $70 \%$ combination of cumulative talk and exploratory talk are rated as either "mid-quality" or "low quality". The double threshold for a "mid-quality" conversation is set at a minimum of 500 words and 50\% on task activity; whilst paired conversations below this double threshold are deemed to be of "low quality". The findings are outlined below in Table 2 .

As outlined above, within the eleven conversations ${ }^{6}$ the students from Apostle High are on task for an average of $69.6 \%$. This mean average, though, does mask a wide variety of returns. Broadly speaking, these eleven conversations are classified into three categories i.e.

- 6 high quality conversations (nos. 1, 2, 8, 9, 10 and 11);

- 1 mid quality conversations (no. 12); and

- 4 low quality conversations (nos. 3, 4, 6 and 7).

Let us examine the "high quality" Apostle High conversations in some more detail.

\footnotetext{
${ }^{6}$ For paired conversation no. 5 the recording was corrupt and unusable.
} 


\subsection{Preliminary analysis of conversation no. 1}

\subsubsection{Y13 Lucy (agnostic) and Alice (atheist)}

There $^{7}$ are $^{8} 2536$ words in their passage of conversation about the historical evidences excerpt. In terms of cumulative talk and exploratory talk, the two students are on task for $86.9 \%$ of this conversation. With respect to cumulative talk, Lucy and Alice build upon each other's comments regarding their common distrust of eyewitness accounts and Old Testament stories and their suspicion of miracles. With regard to exploratory talk, Alice and Lucy challenge the apparent lack of evidence underpinning the scholarship that claims the Gospels were written at an early date. They also question the authority of the Old Testament and, without mentioning it by name, the magisterium of the Catholic Church regarding which passages of Scripture should be taken literally; and which are to be understood metaphorically.

\subsection{Preliminary analysis of conversation no. 2}

\subsubsection{Y13 Jasmine (agnostic) and Tilly (practising Catholic) [1]}

There are 2215 words in their passage of conversation about the historical evidences excerpt. In terms of cumulative talk and exploratory talk, Jasmine and Tilly are on task for $94.0 \%$ of this conversation. With respect to cumulative talk, Jasmine and Tilly share a commonality of views concerning miracles, God as a cause for creation and evolution, and the afterlife. With regard to exploratory talk, Tilly offers metaphor as a key to understanding the Genesis story and posits the design argument as a feature of the universe; and they struggle together about a modern-day concept of sin and its consequences.

\subsection{Preliminary analysis of conversation no. 8}

\subsubsection{Y13 Jim (agnostic) and Tom (Catholic) [1]}

This passage of conversation about science and the supernatural has a substantive word count of 2606 words; and in terms of cumulative talk and exploratory talk, it just surpasses the threshold with an on task return of $70.4 \%$. With regard to cumulative talk, they question both the feasibility of interaction with a spiritual dimension and the nature and development of human knowledge at the time of Jesus. With respect to exploratory talk, Jim and Tom question the nature of the after-life and the purpose of free will.

\footnotetext{
7 The students selected names other than their own for participation in this study.

8 The students were invited to declare their (non-) religious affiliation as they perceived it.
} 


\subsection{Preliminary analysis of conversation no. 9}

\subsubsection{Y13 Jim (agnostic) and Tom (practising Catholic) [2]}

This passage of conversation is shorter with 1038 words. In terms of cumulative talk and exploratory talk, the two students are on task for $96.6 \%$ of this conversation. Their conversation focuses on topics such as fate and free will, the role of God, and the nature of truth.

\subsection{Preliminary analysis of conversation no. 10}

\subsubsection{Y13 Leya (Catholic) \& Alexander (agnostic)}

This is a more substantive passage of conversation comprising 1503 words. In terms of cumulative talk and exploratory talk, Leya and Alexander are on task for $99.4 \%$ of this conversation. Jointly they are intrigued by the dimensionality of the universe and they explore the concept of God as creator of this universe. They both adopt a disbelieving attitude towards a literal interpretation of the biblical story in Genesis.

\subsection{Preliminary analysis of conversation no. 11}

\subsubsection{Y13 Lucy and Keira (both agnostic)}

This is a less substantive passage of conversation comprising 965 words. In terms of cumulative talk and exploratory talk, Lucy and Keira are on task for $92.7 \%$ of this conversation. There is very little exploratory talk $(9.5 \%)$ with most of the conversation comprising cumulative talk $(83.2 \%)$ e.g. their agreement that the Bible should be understood metaphorically and not literally.

The classification of these seven conversations as "high quality" is based on the two criteria outlined above i.e. quantity (min. 700 words) and quality of conversation (min. $70 \%$ combination of cumulative and exploratory talk). These dialectical episodes offer rich pedagogical fruit. A teacher of Catholic RE would see opportunities for challenging and deepening their students' worldviews. Upon their return to the classroom, discussion could be given to Church doctrine and teachings within the Catechism of the Catholic Church. These lengthier conversations tend to reveal what students really think and believe-and this affords pedagogic opportunities e.g. an earlier finding from previous research whereby a '...pupil had previously completed a short unit on the topic of abortion, but had given no indication that he held views on abortion contrary to the teachings of the Catholic Church' (Luby 2012, p. 63). The depth of these peer conversations can reveal underlying misunderstandings that the teacher has an opportunity to remedy; otherwise, they go unobserved.

Furthermore, as an experienced practitioner of RE I look upon these conversations and wish that I had been able to engender more such conversations within my classrooms: and I am not alone with this professional judgement. An Assistant Head Teacher (and Head of Religious Studies) at the other Catholic school within this study, Angel High, read a "high quality" paired conversation from her Y10 students and commented: 
When I read it, they actually both showed the kind of open mindedness that I would expect from them... And they were both quite willing to engage with the idea I thought... I think that they bounced off each other quite well... I think they listened... but I think they engaged with it well. Um... I think they were trying to have a genuine conversation about whether there is another world. Um... I think there was some attempt to build on each other's conversations as they went along. And to engage with the new ideas and move them forward.

The only concerns expressed by the Assistant Head Teacher were to do with the practicalities of students engaging in paired conversations outside of the classroom-and this is addressed below. Further corroboration comes from an experienced Head of Religious Studies at another school, Municipal Borough, who undertook a similar exercise of examining her Y9 students' transcripts and voiced the following sentiments:

You are getting pupils to really engage in the topic and I think it's very difficult in a class situation where pupils can express their views clearly; they might have them hidden within them but they're too scared to show them, they're scared of being nerdy for example. I think honestly it's just excellent, it's so nice to see them doing critical thinking in a way. Critical thinking skills.

Notably, both heads of departments had positive responses and indicated that their students were "engaged" with the topic of conversation. Moreover, the Municipal Borough head of department further expresses her pleasure at the students 'doing critical thinking.' So there is some evidence from the professional judgements of three experienced RE teachers that paired conversations do promote student engagement and critical thinking. This level of conversation is deemed high quality: what, though, of conversations that are termed mid-quality or low quality?

\subsection{Preliminary analysis of conversation no. 12}

\subsubsection{Y13 Lucy \& Keira \& Alexander (all agnostic)}

There are 1832 words in this passage of conversation. A timetabling clash meant that another student had to return to class and this presented an opportunity for a triple conversation. Disappointingly, the students are off task for a sizeable part of the conversation with a discussion about racism. Thus in terms of cumulative talk and exploratory talk, the three students are on task for $58.1 \%$ of this conversation.

\subsection{Preliminary analysis of conversation no. 3}

\subsubsection{Y13 Leya and Coraline (both Catholics)}

This is a substantive passage of conversation comprising 2765 words. However, disappointingly, in terms of cumulative talk and exploratory talk the two students are on task for only $38.7 \%$ of this conversation. The majority of the conversation is disputatious and cumulative talk comprises a mere 140 words or $5.1 \%$. Admittedly, though, there are genuine attempts at exploratory talk as evidenced by the 929 words that comprise $33.6 \%$ of their conversation. But overall, much of their conversation runs down side tracks such as the veracity or otherwise of 
the moon landings; the complexity of Scottish history, especially the Battle of Stirling Bridge; and even a zombie apocalypse!

\subsection{Preliminary analysis of conversation no. 4}

\subsubsection{Y11 Sunny (Catholic) and Harambe (agnostic) [1]}

There are 847 words in their brief passage of conversation and, in terms of cumulative talk and exploratory talk; the two students are on task for $29.4 \%$ of this conversation. Compared with conversation no. 3 above there is a higher percentage of cumulative talk; but they waste much time on what can be termed nonsensical talk. Furthermore, there are only 63 words or $7.4 \%$ of the conversation that can be termed exploratory talk.

Conversations 3 and 4 are the types of dialogue about which a teacher is likely to be concerned. On the one hand, with conversation no. 3 there is a personality clash as the two students spend much of the time in disputation; but this can be addressed by the teacher taking care in the selection of partnerships. On the other hand, with conversation no. 4 there appears to be little attempt to take the activity seriously. A classroom teacher would be very disappointed with the lack of quality in both conversations; and with conversation no. 4 a teacher may resort to disciplinary measures concerning the students' behaviour.

\subsection{Preliminary analysis of conversation no. 6}

\subsubsection{Y13 Jasmine (agnostic) and Tilly (Catholic) [2]}

There are 997 words in this passage of conversation that is, overall, of poorer quality than their previous conversation (see no. 2). In terms of cumulative talk and exploratory talk, Jasmine and Tilly are on task for $39.1 \%$ of this conversation. Much of this conversation is disputational and, whilst discussing freewill, Jasmine and Tilly become fixated upon arguing about the role of fate with regard to finding true love.

\subsection{Preliminary analysis of conversation no. 7}

\subsubsection{Y11 Sunny (Catholic) and Harambe (agnostic) [2]}

In terms of cumulative talk and exploratory talk, the two students are on task for $60.1 \%$ of this conversation, and on this count, it merits a rating of "mid quality". However, there are a meagre 379 words in this brief passage of conversation, and much of this discussion focuses on the cult film The Matrix with only a tangential link to RE.

\subsubsection{Preliminary findings}

With regard to answering the first research question- "to what extent do the students remain on-task when their conversations take place out with the visible control of the teacher?"- a straightforward answer is $69.6 \%$. However, as outlined above, there is a high degree of variability within these conversations. Six of the conversations are exemplary with no less than an average of $94.6 \%$ of the time spent on both cumulative talk and exploratory talk. This student talk focused on a breadth of topics, amongst them- 
Table 3 Faith schools quality of conversations $(n=27)$

\begin{tabular}{lcll}
\hline School & High quality & Mid quality & Low quality \\
\hline Apostle high & 6 & 1 & 4 \\
City Catholic School & 4 & 0 & 0 \\
County C of E Academy & 1 & 4 & 1 \\
Magdalene C of E Academy & 5 & 1 & 0 \\
Total & 16 & 6 & 5 \\
\hline
\end{tabular}

Source Luby (2019)

Literal and metaphorical understandings of biblical stories;

Miracles

Creation and evolution

Heaven and hell

Reincarnation

Judgement

Fate and free will

Nature of truth and

God as creator

One of the conversations is classified as "mid-quality" and includes discussion of metaphor, historical influences, and racism. Arguably, given this set of seven conversations, then many RE teachers in Australia who teach senior students might consider adopting such dialogic pedagogy. However, the four remaining "low quality" conversations give pause for thought. These conversations have an average of only $41.8 \%$ on task activity that comprises cumulative talk and exploratory talk. Indeed, some of the conversations are bedevilled by disputatious or nonsensical talk. Hence, the findings from the other nine schools in the study require analysis before arriving at a firmer set of conclusions.

\section{Other faith schools}

The second Catholic school in this study is the City Catholic School that is an Ofstedrated "Outstanding" secondary school in which more than $80 \%$ of students are baptised Catholics. The school serves a wide, mixed area of the city with some areas of significant disadvantage. The overall ability of students on entry is average whilst the number of students who have learning difficulties and/or disabilities is below average. Fieldwork was undertaken with four students in Y13 all of whom are studying A-level Religious Studies; and they self-declared their religious affiliation as follows:

The first of the other two faith schools is County Church of England Academy which is a smaller-than-average secondary school situated in a village location. The proportion of 
Table 4 Non-faith schools quality of conversations $(n=34)$

\begin{tabular}{llll}
\hline School & High quality & Mid quality & Low quality \\
\hline Acacia lane & 1 & 1 & 4 \\
Angel high & 2 & 3 & 1 \\
Lion Rampant School & 6 & 0 & 0 \\
Metropolitan Borough & 5 & 1 & 0 \\
Municipal Borough & 4 & 0 & 0 \\
Templar School & 6 & 0 & 0 \\
Total & 24 & 5 & 5 \\
\hline
\end{tabular}

Source Luby (2019)

disabled students and those who have special educational needs is above average. Fieldwork was undertaken with seven students-five in Y11 and two in Y10. The students selfdeclared their religious affiliation as follows:

Agnostic

Atheist

The final faith school is Magdalene Church of England Academy which is an average-sized school with a smaller than average sixth form sited within an area of deprivation. The proportion of students known to be disadvantaged is well above that found nationally and is increasing over time. The proportion of disabled students and those who have special educational needs is well above average.

Fieldwork was undertaken with seven students in Y10 and they self-declared their religious affiliation as follows:

Agnostic

Overall then, from the four faith schools there were twenty-seven conversations and their ratings are outlined below in Table 3.

As can be seen, the percentage of low quality conversations has diminished from thirty-six (Apostle High only) to eighteen-and-a-half (four faith schools combined); whilst the percentage of high quality conversations has increased from fifty-four-anda-half (Apostle High only) to fifty-nine (four faith schools combined). This is reassuring; and this reassurance is only but strengthened when considering the thirty-four conversations that took place in the six non-faith schools (see Table 4 below).

The corresponding percentages for high quality and low quality conversations are seventy-and-a-half and fifteen respectively.

In terms of relatability for RE teachers, I would submit that with almost $84 \%$ of the students' conversations rating as either high quality or mid-quality-then it is fair to conclude that in response to research question 1 that the large majority of students remain on task, for the most part, when outwith the visible control of the teacher. 
Table 5 Summary of quality conversations $(n=61)$

\begin{tabular}{lllll}
\hline School types & No. conversations & High quality & Mid quality & Low quality \\
\hline Faith & $(\mathrm{n}=27)$ & 15 & 7 & 5 \\
State/Academies & $(\mathrm{n}=34)$ & 24 & 5 & 5 \\
Total & & -39 & -12 & -10 \\
& & $-(63.9 \%)$ & $(19.7 \%)$ & $(16.4 \%)$ \\
\hline
\end{tabular}

Source Luby (2019)

With regard to the second research question-then it is fair to say that this dialogic RE intervention is likely to promote good levels of participation in cumulative talk and exploratory talk by most students.

\section{Future research and practice}

...Catholic education is primarily a cultural project. It is a means of communicating the Gospel message effectively with a view to enriching the cultural atmosphere of the pluralist society. To do so requires a deep and lasting commitment to dialogue with those who do not share the Christian world view. (Convery et al. 2014, xiii-xiv)

The Glasgow scholars, Convery, Franchi and McCluskey are referring to the Vatican initiative Courtyard of the Gentiles which seems to act as a progenitor for the Congregation for Catholic Education (2017, Para. 14) and its document Educating to fraternal humanism in which it attests that:

Education to fraternal humanism has the weighty responsibility of providing a formation of citizens so as to imbue them with an appropriate culture of dialogue. Moreover, the intercultural dimension is frequently experienced in classrooms of all levels... so it is from there that we must start to spread the culture of dialogue.

The evidence presented within this paper indicates that the RE classrooms of UK secondary schools are appropriate places to begin to "spread the culture of dialogue." Given that Australia is at the forefront of the Recontextualising Dialogue School Model (Boeve 2016; Pollefeyt and Bouwens 2010, 2014, 2017) then these research findings should be of interest to educators in Australia. Should they wish to take forward the implementation of the dialogic skills of cumulative talk and exploratory talk in RE classrooms; then they may wish to adopt the "snowballing" technique. Prior to their conversations, set the students in pairs who are comfortable talking with each other. Issue them with a prompt sheet (see Fig. 1 above) clarifying the contents and ensuring that they understand. Allow the prompt sheets to be retained by the students who should be encouraged to refer to them throughout their conversations. In order to initiate their conversations, have the students read a challenging but not overly demanding text; and allow their conversations to wander should they so want. After ten minutes or so, ask the pairs to identify two or three main points from their conversations that they are comfortable sharing with others. In groups of four students the pairs can now share and discuss their four to six main points. Again, remind them to refer to the prompt sheet. The concluding plenary session should now provide several examples of cumulative talk and exploratory talk that can be shared with the whole class (Table 5). 
For teachers of RE who are au fait with new technologies then they may wish to examine how apps such as Book Creator, GarageBand, and i-Tunes University can help them to record and analyse their students' conversations. These may be small steps, but nonetheless important steps, that embed dialogic cultures within classrooms.

Open Access This article is distributed under the terms of the Creative Commons Attribution 4.0 International License (http://creativecommons.org/licenses/by/4.0/), which permits unrestricted use, distribution, and reproduction in any medium, provided you give appropriate credit to the original author(s) and the source, provide a link to the Creative Commons license, and indicate if changes were made.

\section{References}

Baum, G. (2000) The theology of Cardinal Ratzinger: A response to Dominus Iesus. The Ecumenist [Electronic] 37(4) Fall 2000. Retrieved from http://www.culture-et-foi.com/dossiers/dominus_jesus/gregory_ baum.htm. Accessed 31 May 2016; subscription now required.

Boeve, L. (2016). Theology at the Crossroads of University, Church and Society: Dialogue, difference and Catholic identity. London: Bloomsbury, T\&T Clark.

Carswell, M. (2018). Teaching scripture: Moving towards a hermeneutical model for religious education in Australian Catholic Schools. Journal of Religious Education, 66(3), 213-223.

[CCC] Catechism of the Catholic Church. (1994). London: Geoffrey Chapman.

Congregation for Catholic Education. (1982). Lay Catholics in schools: Witnesses to faith. Vatican: Congregation for Catholic Education.

Congregation for Catholic Education. (2017). [Online] Educating to fraternal humanism. Retrieved from: https ://lnkd.in/dfj_FkZ. Accessed 19 May 2018.

Convery, R., Franchi, L., \& McCluskey, R. (2014). Reclaiming the Piazza. Catholic education as a cultural project. Leominster, Herefordshire: Gracewing.

De Lubac, H. (1995). The drama of Atheist humanism. Trans. E. M. Riley, A. E. Nash and M. Sebanc. San Francisco: Ignatius Press.

Ivereigh, A. (2015). The great reformer: Francis and the making of a radical Pope. London: Allen \& Unwin.

Luby, A. (2006). Prudence and modern culture: A pedagogical perspective. unpublished MTh dissertation. Aberdeen: University of Aberdeen.

Luby, A. (2008). Thomist pedagogy for Catholic RE. Journal of Religious Education, 56(2), 40-44.

Luby, A. (2010). This is our faith: Evangelization, confessionalism and criticality. Journal of Religious Education, 58(2), 37-48.

Luby, A. (2012). Developing dialogic skills for inter faith dialogue. Unpublished MSc dissertation. Oxford: University of Oxford.

Luby, A. (2014). First footing inter-faith dialogue. Educational Action Research, 22(1), 57-71.

Luby, A. (2019). Dominican Thomist Pedagogy for a Post-Secular Society: Developing dialogic skills in RE for UK Secondary School Students. Unpublished PhD thesis. Glasgow: University of Glasgow.

McKenna, U., Ipgrave, I., \& Jackson, R. (2008). Inter faith dialogue by email in primary schools. Munster: Waxmann.

Mercer, N. (1995). The guided construction of knowledge: Talk amongst teachers and learners. Cleveden, Avon: Multilingual Matters Ltd.

Pollefeyt, D., \& Bouwens, J. (2010). Framing the identity of Catholic Schools: Empirical methodology for quantitative research on the Catholic identity of an Education Institution. International Studies in Catholic Education., 2, 193-210.

Pollefeyt, D., \& Bouwens, J. (2014). The identity profile of Catholic Schools in Victoria. Conclusions and recommendations. In D. Pollefeyt \& J. Bouwens (Eds.), Identity in dialogue: Assessing and enhancing Catholic School identity: Research methodology and research results in Catholic Schools in Victoria, Australia (pp. 271-315). Zurich-Berlin: LIT-Verlag.

Pollefeyt, D., \& Bouwens, J. (2017). Wat betekent 'dialoog' in de Katholieke Dialoogschool? What does 'dialogue' mean within the Catholic Dialogue School? In L. Boeve, J. Mettepenningen, \& D. Pollefeyt (Eds.), Liefde in Tijden van Katholieke Dialoogschool (Katholieke Dialoogschool 3) (pp. 21-36). Antwerpen: Halewijn.

Pope Francis. (2013). [Online] Encyclical Letter. Lumen Fidei. 29 June 2013. Retrieved from http://www.vatic an.va/holy_father/francesco/encyclicals/documents/papa-francesco_20130629_enciclica-lumen-fidei _en.html. Accessed 26 December 2018. 
Pope Saint John Paul II. (1990). [Online] Encyclical letter. Redemptoris Missio. On the permanent validity of the Church's missionary mandate. 07 December 1990. Retrieved from http://www.vatican.va/holy_fathe r/john_paul_ii/encyclicals/documents/hf_jp-ii_enc_07121990_redemptoris-missio_en.html. Accessed 07 May 2018.

Pope Saint John Paul II. (1995). [Online] General audience. All Salvation Comes Through Christ. 31 May 1995. Retrieved from https://www.ewtn.com/library/PAPALDOC/JP950531.HTM. Accessed 28 December 2017.

Pope Saint Paul VI. (1965). [Online] Declaration on religious freedom. Dignitatis Humanae. On the right of the person and of communities to Social and Civil Freedom in Matters of Religion. 07 December 1965. Retrieved from: http://www.vatican.va/archive/hist_councils/ii_vatican_council/documents/vat-ii_ decl_19651207_dignitatis-humanae_en.html. Accessed 07 May 2018.

Sherman, F. (Ed.). (2015). Bridges: Documents of the Christian-Jewish Dialogue. Volume two-building a new relationship (1986-2013). New Jersey: Paulist Press.

Publisher's Note Springer Nature remains neutral with regard to jurisdictional claims in published maps and institutional affiliations. 